\title{
Cultivation of College Students' Core Socialist Values Under Micro-Culture Ecosystem
}

\author{
Zhi-Hong LIU ${ }^{1, a,{ }^{*}}$ and Bei ZHU ${ }^{2, b}$, \\ ${ }^{1}$ School of Journalism and Communication, Jiangxi Normal University, 99 Ziyang Avenue, \\ Nanchang City, Jiangxi Province, 330022, China. \\ ${ }^{2}$ School of Journalism and Communication, Jiangxi Normal University, 99 Ziyang Avenue, \\ Nanchang City, Jiangxi Province, 330022, China. \\ a704479752@qq.com, b30602595@qq.com \\ ${ }^{*}$ Corresponding author
}

Keywords: Core Socialist Values; Media Effects; Ideological \& Political Education

\begin{abstract}
In today's mobile life, lacking of micro network literacy, marginalizing of main discourse power, getting worse of education approach effects turned to be ubiquitous problems of ideological and political education in most Chinese colleges. Thus, utilizing "micro-education" approach in order to cultivate opinion leader students, producing "micro-materials" from niche to public; recreating micro-format from propaganda-oriented to interpretation-oriented; Continuously prompting contemporary college students' media literacy education, developing their micro-culture literacy level, raising up working effects on cultivating college students' core socialist values substantively, reforming mainstream discourse power in this education field turns to be more significant.

*This research was a phased achievement which financially supported by the University Humanities and Social Sciences Research Projects of Jiangxi Province (No. SZZX1736).

\section{Introduction}

Ideological and Political Educators (or "IPEs" for short) meet both opportunities and challenges in recent context of micro media culture [1]. For the contemporary students, it is plausible to believe that less of them actually understand the internal meanings of the core socialist values (or CSVs, for short) [2], hence, it becomes a supreme task for IPEs to develop and reinforce the "arriving” effects of CSVs on students.
\end{abstract}

\section{Features and Forms of Micro-culture}

Micro-culture is an emerging cultural ecosystem powered by smartphones, panel computers and other kinds of mobile devices usage, dominate information platforms are social network service providers like Weibo and Wechat, they are micro-capacity, multi-channels and easy-sharing in some extents. Micro-culture media reduces the distance between students, and turns to be the principle communication channels for its particular characteristics like openness d ductility and instantaneity. On one hand, micro-culture modifies the existing communication modes of students, correspondingly, forms a so called "peer to peer" communication networks which weaken the power of official discourse. On the other hand, the progress of today's society makes the statement "everyone has a microphone" possible, thus IPEs face series of difficulties, for example, the change of audience themselves, the less control on channels, the obsolescence of content and so on.

\section{Cultivation Dilemma of Students' Core Socialist Values}

This study is an exploratory quantitative research which presented some descriptive statistics information around the relevant topic, data were collected based a small size campus survey $(\mathrm{N}=140$, 
56\% for Females). Most students (63.6\%) claimed that they were not clearly know or recognize the foci of the CSVs, with $22.8 \%$ of them further asserted that "it is not relevant with their business"(see Fig. 1).

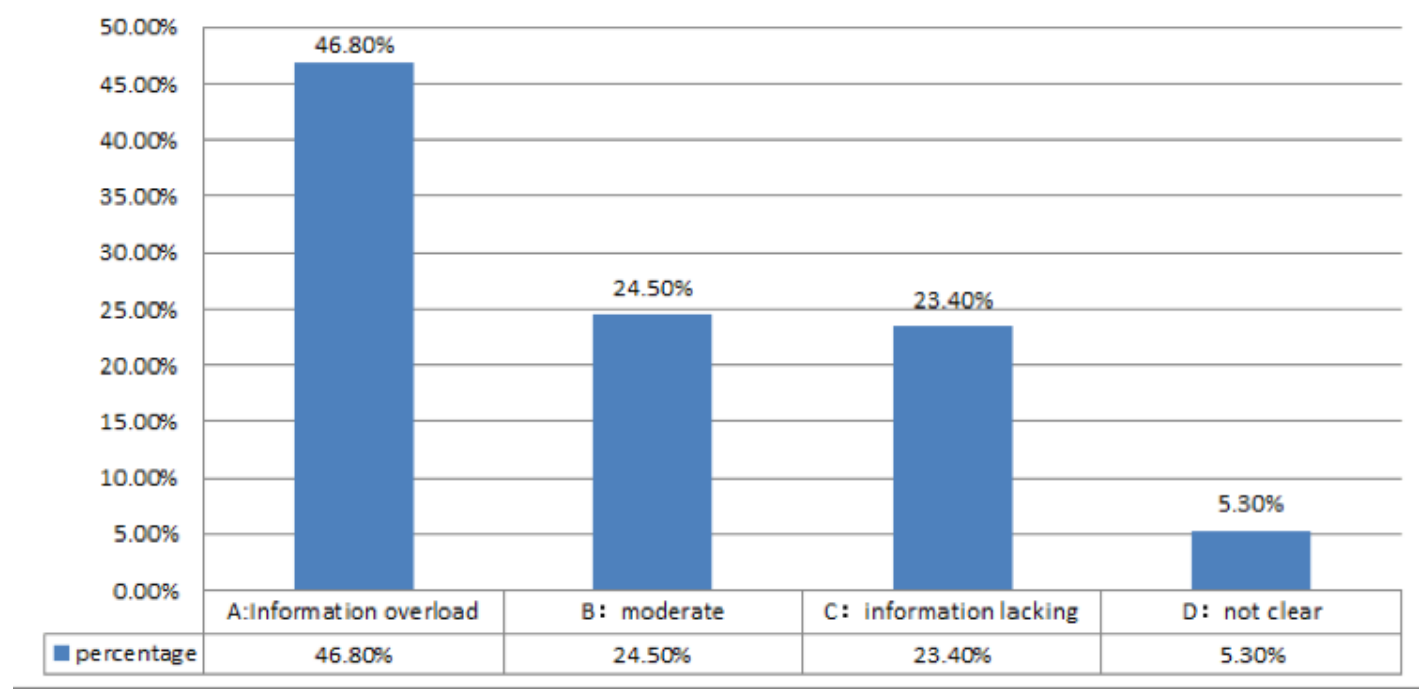

Fig. 1: users' satisfaction level on new media (like Wechat, Weibo)

\section{Marginalization of Ideological and Political Education Channels}

The question "would new media, like Weibo and Wechat, could meet your communication needs?" was adopted in the questionnaire. Results showed that $46.8 \%$ of respondents thought those media were information overloading, while $23.4 \%$ of them felt they are insufficient (see Fig. 2).

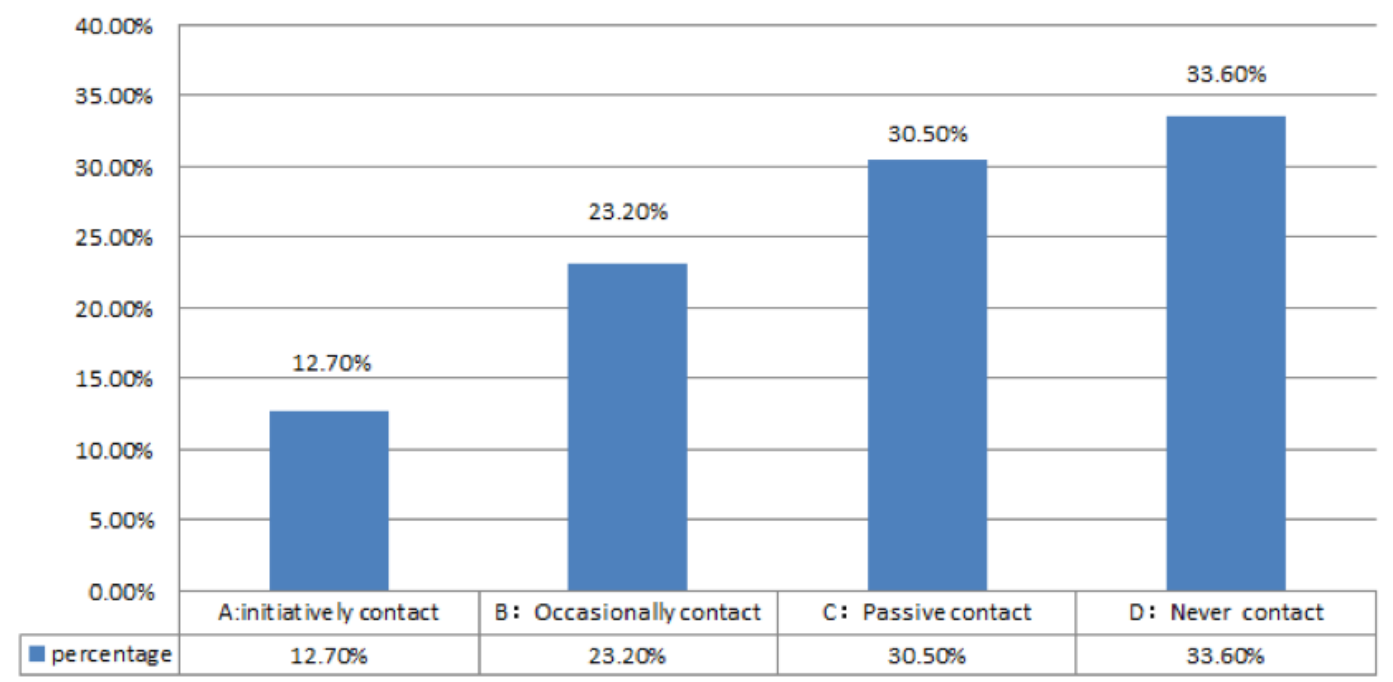

Fig. 2: Users exposure frequency of Ideological \& political-relevant contents

In terms of students' political information exposure and related behaviors, the result showed only $12.7 \%$ students would "focus and scan information consciously"; $23.2 \%$ students "pay attention occasionally". Moreover, 30.5\% students expressed that the process of information receiving was passive and boring, and 33.6\% of them said that they never pay attention on this kind of information. In contrary, students used those media for several purposes, for entertainment news (26.2\%), sports and electric competition (22.6\%), literature and vogue (23.1\%), current political affairs (18.9\%) and the rest for $(10.1 \%)$ for another issues. 
When talked about their attitudes toward articles which related to ideological and political education, most students (51.6\%) thought they are unpractical for problem solving, and $25.2 \%$ of them maintained that the forms are inflexible, and also, the rest (23.2\%) thought the content are monotone (see Fig. 3).

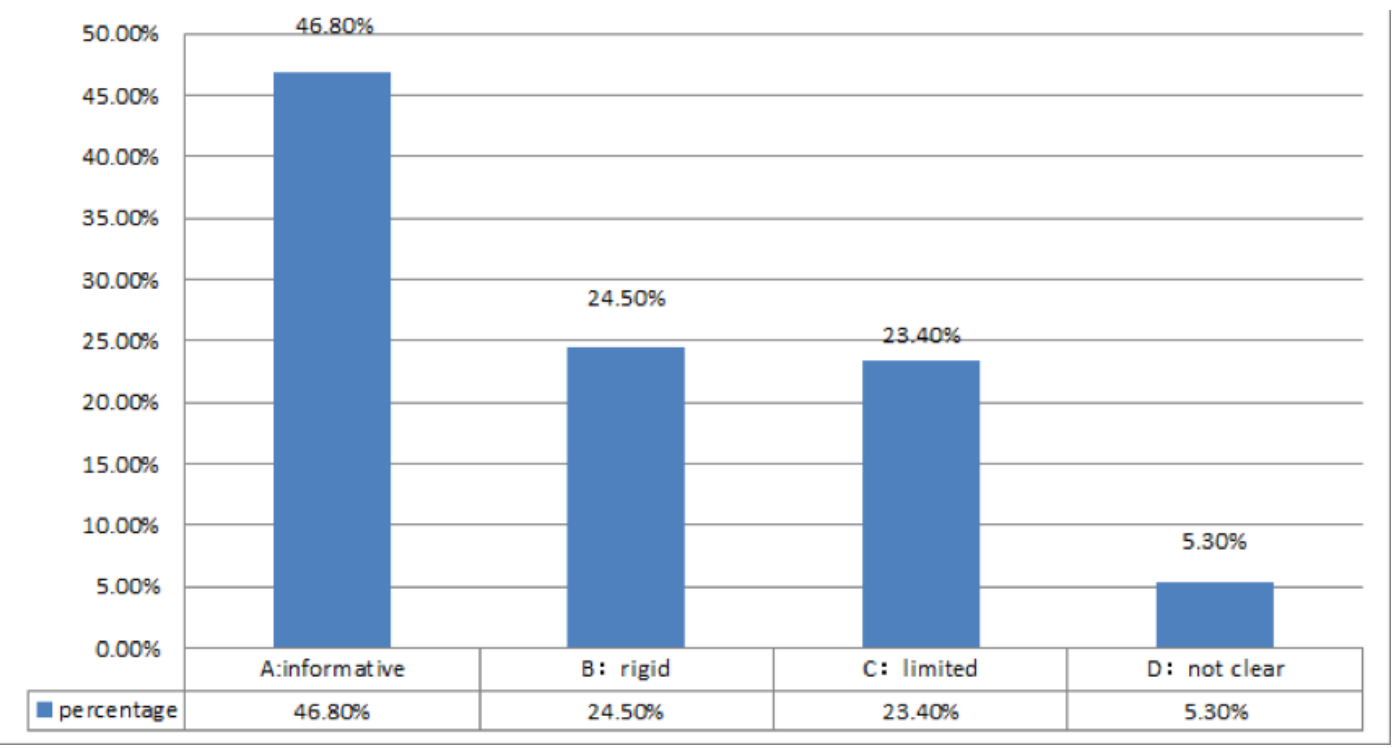

Fig. 3: attitudes toward articles related to ideological and political issues

Apparently, ideological and political information became less and less popular among students, even more turned into fringe stage. Beside, college students' have multiple options for information acquiring under the micro-culture background, information overloading became a common situation. Students' reading habits also varied, their scanned online information in short time span, with higher frequency and tend to enjoy those contents in pieces. However, these fragmented-style usage habits leaded to skepticism or extreme bias in some extents, students became extreme highly subjective when selecting information, although they always claimed to be open to diverse information. In the context of this study, this phenomenon aroused our worries on students' lack recognition on SCVs.

\section{Education Effects Lies on Students’ Network Literacy}

In the "user generate content" era, college students showed less interests on mainstream stories but were keen on disseminating destructing entertainment information, some popular tales were posted online, for example, "the story of QIU Shaoyun was contrary to scientific cmmon sense", "extramarital affairs cause Da Yu confusing back home”," poet LEE Bai was the biggest rogue in Tang Dynasty". Except the imputation of national heroes, some phenomenal views like "new liberalism", "Marxism is out of date” were also emerged. It was not only affected contemporary students' values and daily decision-making, but also brought the risk of marginalizing the national mainstream culture.

Based on the long-term of educational experience, we may figure out the possible positive relationship between students' network literacy and the effects of ideological and political education, from an intuitive perspective, namely the increase of students' network literacy would promote their understanding and critical thinking on information, while relevantly benefit the progress of political education.

\section{Reasons of Why Traditional Education Methods were unstuck}

"people talk and communicate upon the basic of equality, reach to agreement finally through understanding”, socialist Habermas (1984) wrote in his book 《Theory of Communicative Action》 
[3]. However, educators always regarded themselves as the subjects and students as the objects, there was no actual equal communication between two sides. "Spoon-feeding" was considered to be the "best solution", but with the continuous development of students' self-awareness, the traditional way was coming to the end.

Besides, the Internet was treated as as a "displacer" while the voice online sometimes replaced the active status of educators, "micro-culture" also deconstructed the long-term discourse power of mainstream. But this was not only caused by the "incorrectly use of Internet", but also may caused by the educators themselves. Some existing studies showed that some educators were less awareness, lack of teaching abilities and also have insufficient practice[4], and all those problems could totally be extracted as a lack of 'micro-literacy' in general. More specifically, "less Attention” refers to their insufficient preparation to be key opinion leaders among students; "Lack of Abilities" refers to their bad use of new media serve for a better work efficiency; and "Insufficient Practice" refers to their slow reaction and work strategies.

\section{Micro-Culture Challenges the Methodology of IPE}

In order to meet the further requirements of the Party Central Committee, educators need to establish the moral education curriculum system, develop study materials and reform teaching approaches under the micro-culture background.

Firstly, adopting persuasion-centered education method rather than the infusion-based method. The traditional way always operated ideological and political theory courses, used specified curriculum materials, and the educators controlled the class while students have rare opportunities to express their opinions. If educators only focused on mono-directional persuasion while neglected bilateral persuasion, it would lead to dis-satisfied outcomes; Secondly, emphasizing on effects rather than forms. Although many mobile terminals, such as micro-videos, diagrammatizing as well as Html5 were popular, they are good new tries to adopted into education, but the new forms are not the foci, educators should not only cares "information issuing” but overlooked "information receiving"; Thirdly, putting more efforts on updated practice. Curriculum materials used by most educators have several problems: outdated contents, simple forms and less realistic sense, students always treated the course as a compulsory task, hence they showed lower enthusiasm and initiative.

\section{Measures of Reinforcing Education Effects Under Micro-Culture}

First, consolidating official media's discourse power by initiatively embracing the "micro". Educators should aware that students nowadays are totally new, they have different communication trends and behaviors, more self-awareness and highly critical than before. Educators, however, should refresh their styles in educational forms, contents, channels in micro levels. That means, grasping the chance of media integration, reaching the goal of "universal coverage" and taking works in the governance and supervision, cutting down the disseminating of "bad contents".

Second, constructing college ideological education micro ecosystem with the help of micro-culture. It implies in two aspects: the one is about fostering opinion leaders in college networks, and the another is about encouraging and guiding college ideological educators (i.e. theoretical researchers and political tutors) to learn and use 'micro-communication' tools (i.e. Wechat and Weibo). Changing the current silence situations of educators in the 'micro-environment', guiding opinion directions and fostering positive and health opinion phenomenon in school are needed.

Third, digging out the "micro-materials", from niche to public. Students would like to accept some contents that called "positive energy" with exerting peer-education effect, that means spreading daily stories through students themselves.

Forth, Innovating "micro-form” from propaganda to interpretation. Generating and disseminating contents of socialist core values should obey the rule of easy-reading, that means it will be better for educators to help students accepting and understanding with their favorite way. 
The last but not the least, developing "micro-literacy" with prompting students' literacy education. The micro-culture literacy is a sort of knowledge-type ability of adapting to micro-culture environment and progressing direction, includes dialectical capacities, critical thinking skills and involvements in micro-culture. Currently, although we could not deny the improvement of college students' micro-culture literacy, we still need to focus on the existing problems like fuzzy understanding and weak critical thinking ability of students. Some practical advices have been given for deconstructing these sickness, they are: Students should reinforce self-control, treat the influence of micro-culture objectively; Students should emphasize on their study(courses), advancing their network self-control ability and Internet ethic distinguishing ability; Students should protect themselves from bad information, never follow, forward or comment rumors and negative contents; Students should utilize times reasonably, refuse consuming too much time and energy on Internet; Students should regard micro-culture as a platform for knowledge gaining, and validly use series of micro-tools with the convenient of micro-culture.

\section{Discussion and Conclusion}

The popularity of micro-culture sets up brand new environment for socialist core values education. Under such circumstances, it is an important issue that how to takes fully inherent advantages of micro-culture on spreading and promoting socialist core values to advance them into curriculum material, class and finally into students' mind. Aims to direct student on learning, approving and practicing socialist core values, we are obliged to strength the study and probe concerning micro-culture to provide better services for socialist core values education career.

\section{Acknowledgement}

This research was a phased achievement which financially supported by the University Humanities and Social Sciences Research Projects of Jiangxi Province (No. SZZX1736).

\section{References}

[1] Lu Shangyue, College Micro-Culture Construction Under the Perspective of Ideological and Political Education. Journal of Culture Study, (2015)03:6-12.

[2] Pei Wenjia.,The Study of College Students’ Ideological and Political Education Effects Under Micro Network Culture Background. Ph.d. Dissertation of Jin Lin University, (2015).

[3] Habermas, J., The Theory of Communicative Action, (1984) Vol. 1: Reason and The Rationalization Of Society.

[4] Regard Cultivating and Practicing Socialist Core Values as the Fundamental Project of Nation Cohesion. People’s Daily (2014-2-26). 